\title{
A PAISAGEM COMO CONDICIONADORA DE BORDAS DE FRAGMENTOS FLORESTAIS
}

\author{
Bethania Cristiane Herrmann*, Efraim Rodrigues**, André de Lima*** \\ * Eng ${ }^{\mathrm{a}}$. Agrônoma, M.Sc., Curso de Pós-Graduação em Agronomia, UEL - bethaniach@yahoo.com.br \\ ** Eng. Agrônomo, Depto. de Agronomia, UEL - efraim@uel.br \\ *** Geógrafo - andlima pr@yahoo.com.br
}

Recebido para publicação: 14/05/2003 - Aceito para publicação: 20/04/2005

\begin{abstract}
Resumo
A paisagem como condicionadora de bordas de fragmentos florestais. Fragmentos florestais diferem em sua estrutura espacial afetando a composição de espécies em suas bordas. O objetivo deste trabalho foi analisar a influência dos índices da paisagem sobre as bordas de fragmentos florestais próximos à cidade de Londrina - PR. As características estruturais dos fragmentos aqui consideradas incluem área, forma, área central e índice de área central; e as características estruturais da paisagem: área da classe, tamanho médio e coeficiente de variação do tamanho dos fragmentos de floresta, distância média até o fragmento florestal mais próximo e total de bordas de floresta. A relação entre composição de espécies, fragmentos florestais e índices de paisagem foi estudada através de Análise de Correspondência Canônica. Os índices de maior importância foram: área, forma e área central dos fragmentos. Godoy, fragmento com 2371,14 ha e inclui o Parque Estadual Mata dos Godoy, apresentou maior variação na composição de espécies quando comparado com os demais.

Palavras-chave: estrutura da paisagem; efeito de borda; diversidade de espécies.
\end{abstract}

\begin{abstract}
The landscape as conditioning of edges of forest fragments. Forests fragments differ in their spatial structure afecting the species composition of edges. The objective of this paper was to analyze the influence of some landscape index over sapling species composition in edges of forests fragments near Londrina - PR. The spatial structures of fragments considered in this paper involved area, shape, core area and core area index; and the spatial structures of landscape: class area, mean patch size, coefficient of variation of the size of the patch (\%), mean nearest neighbor distance and total edge of forest. The relationship between sapling species composition, forests fragments and landscape index were evaluated through Principal Components Analysis. Godoy, fragment with 2371,14 ha showed more variation in the species composition when compared with other fragments.

Keywords: landscape structure; edge effect; species diversity.
\end{abstract}

\section{INTRODUÇÃO}

A riqueza e a abundância de certas espécies florestais dependem das características estruturais dos fragmentos para existirem (Metzger, 2000). Estes fragmentos possuem uma região de contato entre a área ocupada com agricultura ou pastos e o fragmento de floresta, denominada borda, sujeita a diferentes fenômenos ecológicos como quantidade de luminosidade, umidade, densidade de plantas, composição de espécies vegetais, entre outros (Rodrigues, 1998b).

Em fragmentos florestais de formato quadrado, com efeitos de borda se estendendo até $100 \mathrm{~m}$ para o seu interior (Schierholz, 1991), se estes possuírem 1 ha sofrem o impacto total do efeito de borda, os de 10 ha são atingidos em quase $90 \%$ de sua área, os de 100 ha têm $35 \%$ da área afetada e mesmo nos de 1000 ha o impacto é de mais de $10 \%$.

A fragmentação age fundamentalmente reduzindo e isolando as áreas propícias à sobrevivência das populações, levando a extinções de espécies.

A região de Londrina - norte do Paraná (área do presente estudo) sofreu grande fragmentação para abertura de cidades, campos agricultáveis e pastagens. De acordo com Metzger (2000) essa 
fragmentação florestal implica em alta densidade de bordas numa paisagem, e influencia fortemente a diversidade de espécies e composição de comunidades de árvores.

Segundo Rodrigues (1998a), utilizando a mesma área deste estudo, as bordas de fragmentos grandes (maiores que 10 ha) têm composições de espécies diversas das bordas de fragmentos menores. E ainda, estes menores, possuem toda a sua área afetada em termos microambientais, o que reflete também na riqueza de espécies nas suas bordas (Schierholz, 1991).

Além do tamanho, a forma dos fragmentos também influencia o grau do impacto do efeito de borda, incluindo os fluxos bióticos e abióticos (Farina, 1998). A forma pode ser avaliada através de proporções simples entre área de borda e área do fragmento, podendo ser regulares ou irregulares (mais afetados por bordas, implicando diretamente na dispersão de plantas).

Segundo Metzger (1999b), se houver relação entre a presença e a ausência de uma determinada espécie sensível à fragmentação com determinadas características espaciais dos fragmentos-habitats, então este modelo pode ser útil na indicação de fragmentos prioritários em termos de conservação.

As estruturas de isolamento dos fragmentos agem negativamente na riqueza de espécies ao diminuir a taxa de imigração. Estas estruturas podem ser divididas em duas classes: as que medem o isolamento de um único fragmento, em geral através de medidas simples de distância, e as que medem o isolamento médio em relação a todas as áreas de uma determinada unidade da paisagem, através de medidas de proximidade (Metzger, 1999b).

A diversidade de espécies nas bordas pode variar fortemente entre os fragmentos devido a sua estrutura e o seu isolamento, sendo negativa a relação entre diversidade de espécies e grau de isolamento. É possível haver diferenciação na utilização de bordas por espécies, ou as bordas podem ter propriedades seletivas, inibindo a dispersão de algumas espécies e facilitando a de outras. A relação entre estrutura da paisagem e diversidade de espécies de árvores é influenciada pelas características das espécies e a escala de análise (Metzger, 2000).

O presente trabalho teve como objetivo o estudo da influência dos índices da paisagem sobre a composição de espécies de arvoretas em bordas de fragmentos florestais. Nesta perspectiva, nove índices, como citado acima, foram analisados: a área do fragmento, a forma do fragmento, a área central do fragmento, o índice de área central do fragmento, a área da classe floresta, o tamanho médio dos fragmentos de floresta, o coeficiente de variação do tamanho dos fragmentos de floresta, a distância média até o fragmento florestal mais próximo e o total de bordas da classe de floresta.

\section{MATERIAL E MÉTODOS}

\section{Área de trabalho}

A área de trabalho está situada no norte do Paraná, a aproximadamente $23^{\circ} \mathrm{S}$ de latitude e $50^{\circ} \mathrm{W}$ de longitude. O clima da região, classificação de Koeppen, é do tipo Cfa, ou seja, clima pluvial quentetemperado com o mês mais quente apresentando temperatura maior que $22{ }^{\circ} \mathrm{C}$, sempre úmido, precipitação maior que $600 \mathrm{~mm}$, sendo a precipitação média anual em torno de $1.604 \mathrm{~mm}$, alternando em alguns anos com CWA, seco no inverno (Correa et al, 1982). A vegetação é do tipo Floresta Estacional Semidecidual (Veloso e Góes Filho, 1982).

A colonização da região norte do estado do Paraná teve um pico com o estabelecimento da Companhia de Terras Norte do Paraná entre as décadas de 1920 e 1930. Esta companhia e outras similares dividiram a zona rural em pequenos lotes demarcados de tal maneira a terem uma parte de baixada e uma de espigão, contando com água corrente e acesso por estrada de rodagem. Estes lotes ficaram com aspecto de corredores o que influenciou o formato dos fragmentos, muitos deles são quadrados com suas bordas retas, por estarem circunscritos em lotes estreitos (Rodrigues, 1993). Pela época do início do desmatamento e pela maneira como se deu, pode-se afirmar que todas as bordas estudadas possuem a idade aproximada de 70 anos.

A maioria das espécies de arvoretas existentes nesta região está restrita aos fragmentos, pois a área vem sendo desmatada desde a década de 30 para dar espaço a atividades rurais e urbanas. A matriz encontrada nos campos é um mosaico de culturas anuais, sendo as mais importantes: soja, trigo e milho. 


\section{Procedimento metodológico}

O levantamento florístico de arvoretas em bordas de fragmentos florestais foi realizado em 46 transectos, de 18 fragmentos florestais ao redor da cidade de Londrina - PR, dentro de uma área de $60 \mathrm{x}$ $60 \mathrm{~km}$ (Rodrigues, 1998a). Os transectos possuíam até $100 \mathrm{~m}$ de extensão perpendicular à borda (Figura 1). Dependendo do tamanho e da forma do fragmento alguns transectos não chegavam a ter este comprimento da borda até o centro e, devido a este fato, optou-se por diminuir a área amostrada de cada transecto para $40 \mathrm{~m}$ de extensão fazendo assim com que todos os transectos ficassem com a mesma área amostrada, sendo que todos apresentavam $4 \mathrm{~m}$ de largura (detalhes, Tabela 1).

Foram considerados arvoretas e incluídos todos os indivíduos acima de $1 \mathrm{~m}$ de altura e com o diâmetro a altura do peito (DAP) até $5 \mathrm{~cm}$. Todas as plantas foram marcadas com plaquetas de alumínio. Ao todo, em até $40 \mathrm{~m}$ de extensão de todos os transectos dos 18 fragmentos foram amostradas 7861 arvoretas distribuídas em 175 espécies (Rodrigues, 1998a).

Os dados coletados de cada indivíduo foram: altura, DAP e espécie. Os indivíduos foram identificados no Laboratório de Ecologia da Paisagem e no Herbário FUEL - ambos da Universidade Estadual de Londrina. Todas estas informações coletadas sobre os indivíduos foram inseridas no Programa Biota: "The Biodiversity Database Manager" (Colwell, 1999), o qual forneceu uma planilha de abundância de espécies de cada fragmento, no formato "EstimateS".

A estrutura espacial foi quantificada através do processamento de imagem de satélite "Thematic Mapper" Landsat reclassificada que possui as classes floresta e não-floresta. Estas imagens foram obtidas após as etapas descritas na Figura 2.

Tabela 1. Número e comprimento de transectos dos fragmentos, quantidade de plantas e espécies por fragmento.

Table 1. Number and length of transects of the fragments, amount of plants and species for fragment.

\begin{tabular}{|c|c|c|c|c|}
\hline Fragmento & $\begin{array}{l}\text { Número de } \\
\text { transectos }\end{array}$ & $\begin{array}{l}\text { Comprimento dos } \\
\text { transectos }\end{array}$ & $\begin{array}{l}\text { Indivíduo/ } \\
\text { fragmento }^{1}\end{array}$ & $\begin{array}{l}\text { Espécies/ } \\
\text { fragmento }^{1}\end{array}$ \\
\hline Zélia & 2 & 100 & 1128 & 85 \\
\hline Mãe morta & 2 & 80 & 514 & 66 \\
\hline Eucalyptus & 1 & 80 & 443 & 66 \\
\hline Pastejo & 3 & 100 & 693 & 79 \\
\hline Godoy & 8 & 100 & 4774 & 137 \\
\hline Doralice & 4 & 100 & 1917 & 99 \\
\hline Perdidão & 4 & 100 & 1845 & 89 \\
\hline Perdidinho & 2 & 100 & 610 & 54 \\
\hline Broken Elba & 1 & 70 & 110 & 32 \\
\hline Futebol & 2 & 45 & 417 & 31 \\
\hline Vagabundo & 2 & 100 & 589 & 74 \\
\hline Paiquerê-twins & 5 & 100 & 2633 & 111 \\
\hline Placa & 3 & 70 & 959 & 66 \\
\hline Tânia & 2 & 70 & 868 & 61 \\
\hline Paulo & 2 & 50 & 617 & 62 \\
\hline Clube de meninos & 2 & 40 & 509 & 53 \\
\hline Extremo norte & 2 & $75 / 80$ & 520 & 64 \\
\hline Saco cheio & 1 & 100 & 440 & 58 \\
\hline
\end{tabular}

${ }^{1}$ Dados coletados por RODRIGUES (1998a). 


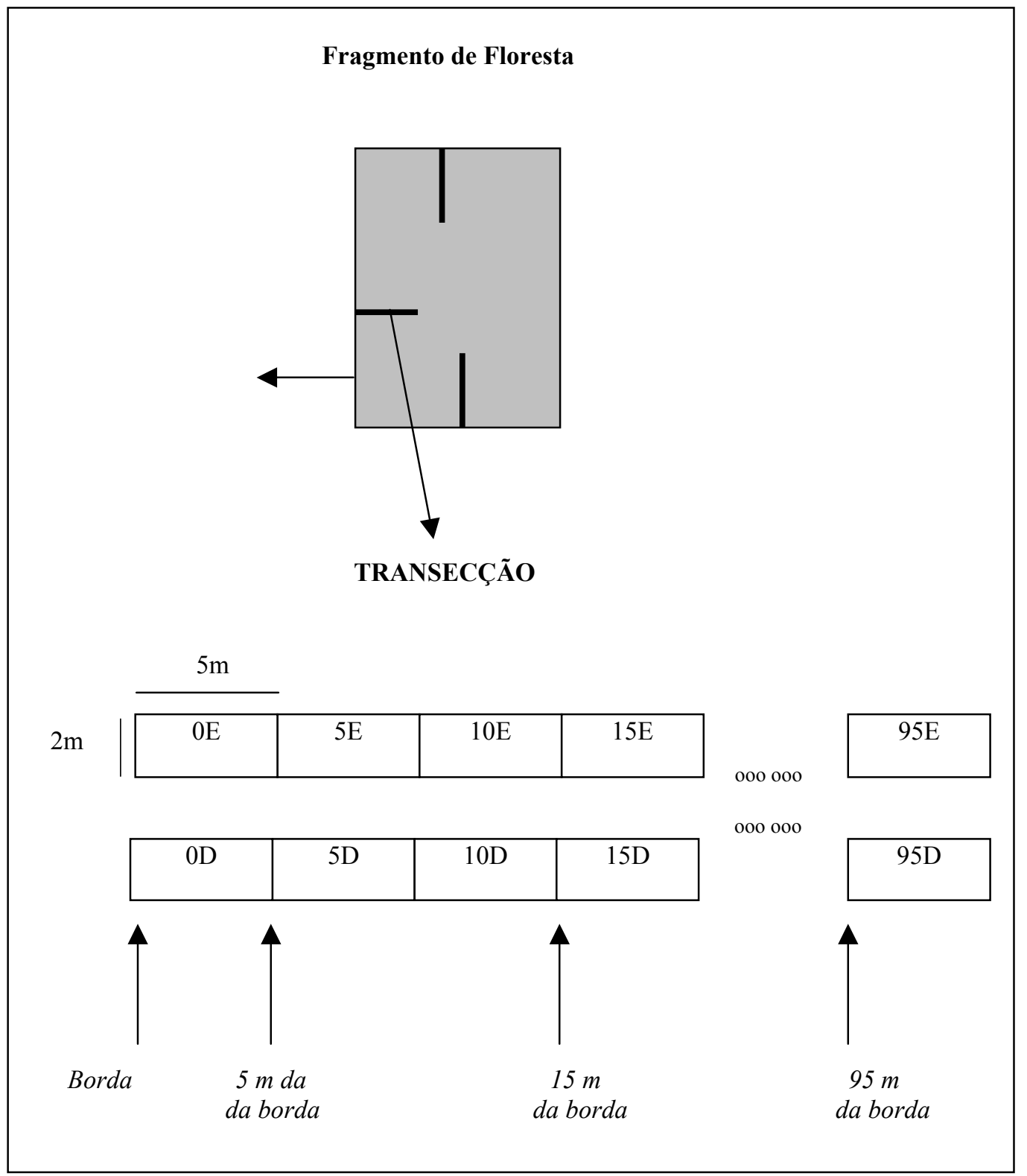

Figura 1. Representação da metodologia de coleta de dados nos fragmentos florestais na região de Londrina - PR. 1998 (Fonte: Rodrigues, 1998a).

Figure 1. Representation of the methodology of collection of data in the forest fragments in the area of Londrina - PR. 1998 (Source: Rodrigues, 1998a). 
Além da conversão de formatos de arquivos TIFF - IMG dos recortes, foram efetuadas no programa Idrisi a eliminação de fragmentos com área inferior a 1ha e a identificação das áreas florestadas e não-florestadas com os valores um e zero, respectivamente. Os fragmentos inferiores a 1ha foram removidos em função da resolução espacial do pixel de $30 \mathrm{~m}$ e, sendo estes fragmentos inferiores a esta área, poderiam ser confundidos com pomares ou pequenas plantações de eucaliptos.

A análise espacial de índices foi realizada a partir do programa Fragstats.

As métricas utilizadas neste estudo foram escolhidas em função do objetivo do estudo, qual seja, uma quantificação adequada da paisagem. As características espaciais escolhidas para analisar os fragmentos e a classe da paisagem, juntamente com as definições das mesmas, (Volotão, 1998) estão na Tabela 2.

Os fragmentos cuja área era inferior a 1ha nas imagens de 1990 tiveram suas métricas calculadas de forma diferente. Estas métricas foram calculadas utilizando fotografias aéreas de 1980. Os fragmentos foram desenhados em papel vegetal e transferidos para uma folha de papel milimetrado, onde sua área foi calculada através da contagem de quadrados milimétricos. O perímetro foi calculado através destes mesmos desenhos ampliados, colocando um barbante em cima da linha que delimitava o fragmento e a partir destes dados calculou-se:

- $\quad$ área(F): resultado da contagem de quadrados no papel milimetrado.

- forma(F): Perímetro

$$
\sqrt{\text { Area } * 4}
$$

- $\quad$ área central(F): Perímetro * Extensão da borda = Área da borda

Área do fragmento - Área da borda $=$ forma $(\mathrm{F})$

- $\quad$ iac(F): Porcentagem da área central.

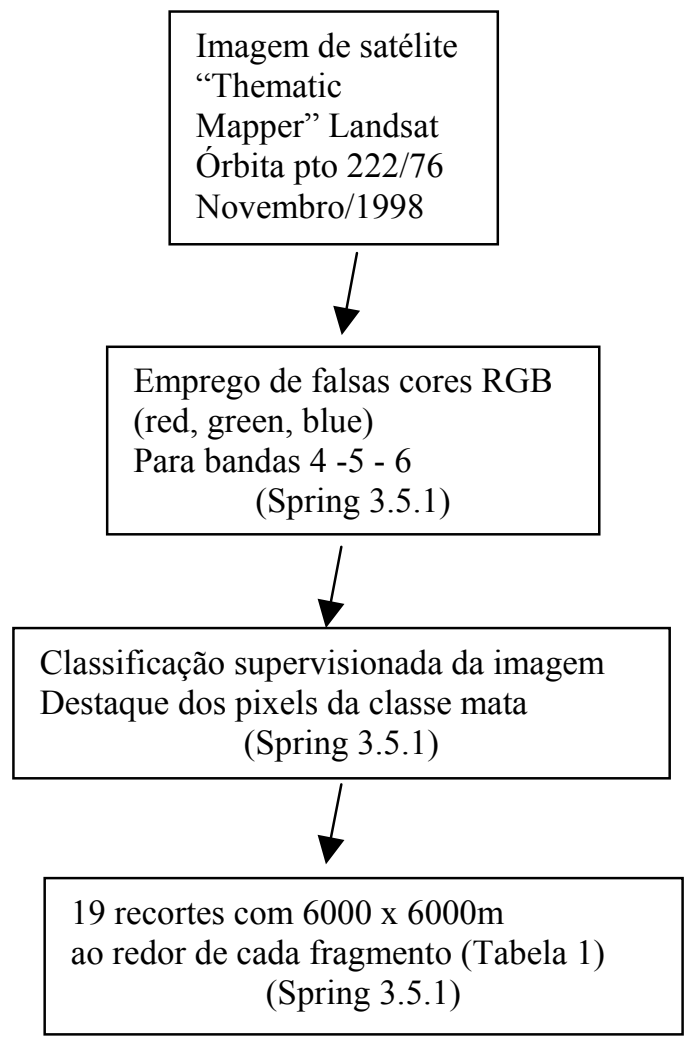

Figura 2. Trabalhos realizados no Spring versão 3.5.1, utilizado na obtenção dos recortes de paisagens.

Figure 2. Procedures accomplished in Spring version 3.5.1, used in the obtaining of the cuttings of landscapes. 
O efeito das métricas da paisagem sobre a composição de arvoretas nas bordas dos fragmentos foi analisado por uma Análise de Correspondência Canônica (ACC) pelo programa PC - ORD Versão 4 (McCune e Mefford, 1999). Em Análise de Correspondência Canônica (ACC), espécies são representadas por pontos e variáveis ambientais (aqui no caso, índices da paisagem) por setas (Braak 1988). A disposição dos índices está fortemente relacionada com a composição de espécies dos fragmentos.

\section{RESULTADOS E DISCUSSÃO}

Os dois eixos do gráfico de Análise de Correspondência Canônica (ACC) explicam no total $73,40 \%$ da variação da composição das espécies nas bordas dos fragmentos florestais. Na Figura 3, estão plotadas a composição de espécies de arvoretas e os índices da paisagem.

Tabela 2. Índices da paisagem utilizados para analisar fragmentos e classe da paisagem e suas definições segundo Volotão (1998).

Table 2. Indexes of the landscape used to analyze fragments and class of the landscape and its definitions according to Volotão (1998).

\begin{tabular}{|c|c|}
\hline Índices & Definições \\
\hline área(F) & $\underline{\text { Área do fragmento em hectares }\left(10.000 \mathrm{~m}^{2}\right)}$ \\
\hline forma(F) & $\begin{array}{l}\text { Índice de forma } \\
\text { Perímetro do fragmento dividido pela raiz quadrada da área e dividido por quatro. } \\
\text { Forma quadrada terá forma igual a um; } \\
\text { Forma circular terá forma }=1,13 \text {; } \\
\text { Forma retangular com lados } \mathrm{X} \text { e } 100 \mathrm{X} \text { terá forma }=5,05 \text {. }\end{array}$ \\
\hline fractal(F) & Dimensão fractal \\
\hline área central(F) & $\begin{array}{l}\text { Área central do fragmento em hectares, excluindo uma faixa de borda de } 35 \mathrm{~m} \text { - valor definido a partir dos } \\
\text { dados de Rodrigues (1998a). }\end{array}$ \\
\hline $\operatorname{iac}(\mathrm{F})$ & $\begin{array}{l}\text { Índice de área central, área central dividida pela área total do fragmento, expresso em porcentagem de áreas } \\
\text { centrais dos fragmentos. }\end{array}$ \\
\hline $\operatorname{ac}(\mathrm{P})$ & $\underline{\text { Área da classe, }}$ ou seja, de todos os fragmentos da classe (floresta) em hectares. \\
\hline $\operatorname{tmf}(\mathrm{P})$ & $\underline{\text { Tamanho médio dos fragmentos, a média entre as áreas de todos os fragmentos da classe em hectares. }}$ \\
\hline $\operatorname{cvtf}(\mathrm{P})$ & $\begin{array}{l}\text { Coeficiente de variação do tamanho dos fragmentos, a raiz quadrada do erro médio quadrático do tamanho dos } \\
\text { fragmentos da classe dividido pelo tamanho médio dos fragmentos. Ou seja, a variabilidade do tamanho dos } \\
\text { fragmentos dividido pelo tamanho médio de fragmentos da classe }\end{array}$ \\
\hline $\operatorname{act}(\mathrm{P})$ & $\underline{\text { Área central total, soma das áreas centrais de toda a classe em hectares. }}$ \\
\hline $\mathrm{tb}(\mathrm{P})$ & Total de bordas, soma do comprimento de todas as bordas de floresta. \\
\hline $\operatorname{dmvp}(\mathrm{P})$ & $\begin{array}{l}\text { Distância média até o fragmento mais próximo, soma de todas as distâncias entre cada fragmento e seu } \\
\text { vizinho mais próximo, dividido pelo número de fragmentos. }\end{array}$ \\
\hline
\end{tabular}

$(\mathrm{F}) \Rightarrow$ Índices para analisar fragmentos.

$(\mathrm{P}) \Rightarrow$ Índices para analisar classe da paisagem, no caso deste estudo, florestas.

Os índices não influenciam diferentemente a composição de espécies nas bordas dos fragmentos, pois os vetores encontram-se todos num mesmo sentido e com poucos graus de diferença nos ângulos entre cada um. O único índice que se encontra com sua direção contrária é o de distância do vizinho mais próximo que mede o isolamento do fragmento, e influencia negativamente na riqueza de espécies ao diminuir a taxa de imigração (Metzger, 1999a, 1999c, 2000), sendo que a maioria dos fragmentos apresenta forte correlação com o índice de distância do vizinho mais próximo, tendendo a serem isolados.

Estão fortemente correlacionados entre si os índices: área, área central e forma dos fragmentos. As métricas de área são muito úteis para estudos ecológicos, pois a riqueza e a abundância de certas espécies dependem das dimensões dos fragmentos da paisagem para existir (Volotão, 1998). O tamanho e a forma dos fragmentos e paisagem podem influenciar inúmeros processos ecológicos importantes. Sua forma pode influenciar processos entre fragmentos, como a imigração de pequenos mamíferos e a 
colonização de plantas de médio e grande porte, e pode influenciar as estratégias de fuga de certos animais, principalmente pela sua relação com o efeito de borda.

Outro grupo de índices também correlacionado foi o índice de tamanho médio do fragmento, área da classe e área central total, todos estes índices são de paisagem (recorte). Observou-se uma tendência de que os recortes que apresentam maior área da classe (floresta) são os que possuem também maiores médias de tamanho de fragmentos, concordando com o descrito por Paula (2001), quando trabalhou com recortes na região norte do estado do Paraná.

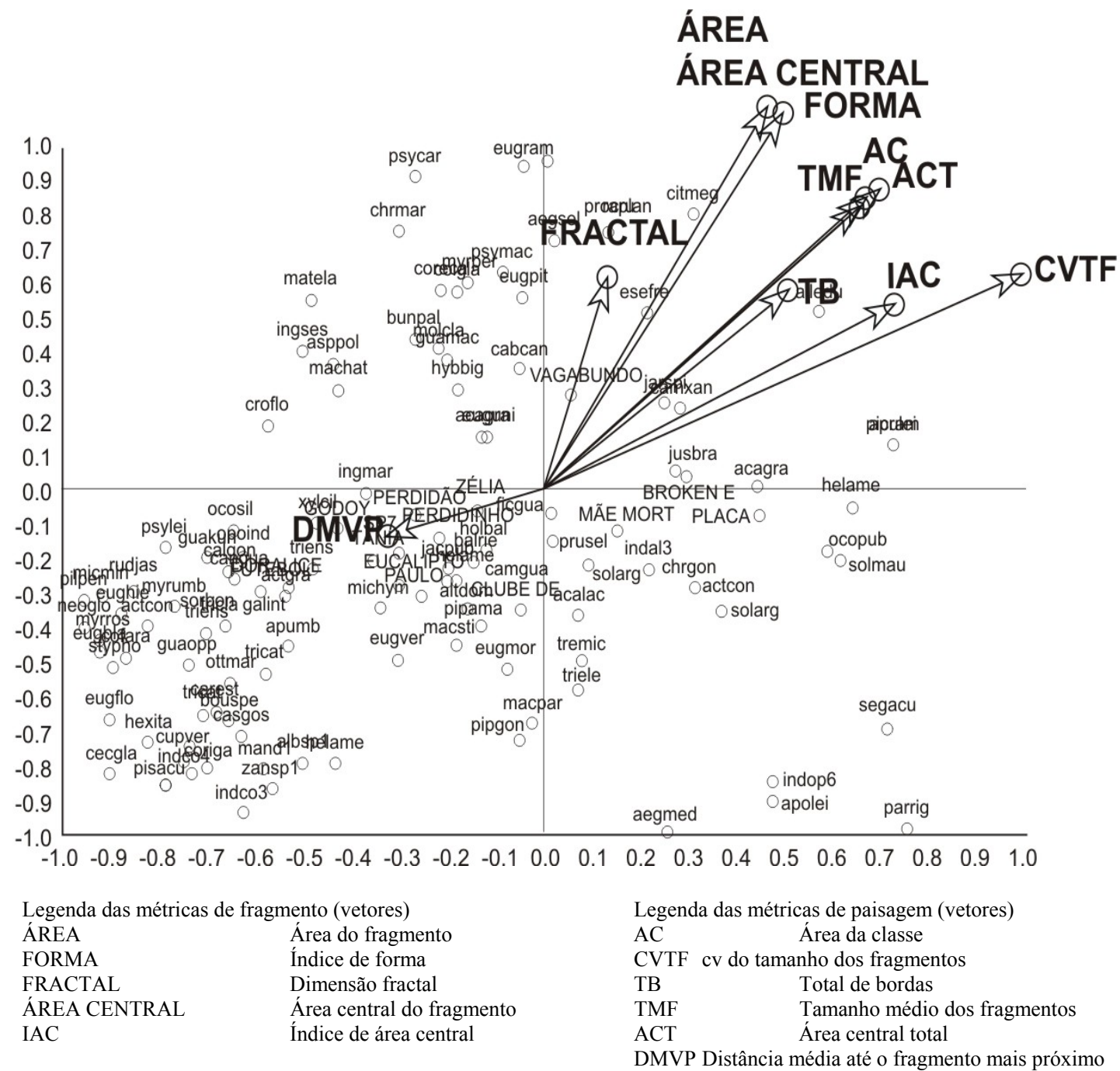

Figura 3. Resultados da Análise de Correspondência Canônica (ACC) entre espécies (letras minúsculas abreviadas), fragmentos (letras maiúsculas) e índices da paisagem (vetores).

Figure 3. Results of the Analysis of Canonical Correspondence(ACC) between species (reduced minuscules letters), fragments (capital letters) and landscape indexes (arrows).

O comprimento dos vetores mostra a correspondência entre métricas da paisagem e as espécies, vetores mais longos apresentam relação mais íntima com o padrão de variação da composição de espécies mostrado no gráfico. O índice (vetor) mais importante por explicar melhor a composição de espécies nas bordas dos fragmentos foi o de coeficiente de variação de tamanho do fragmento, seguido pelos índices de área, área central e forma dos fragmentos. O tamanho dos fragmentos, citado anteriormente, e o grau 
de isolamento dos fragmentos habitat foram considerados os mais importantes parâmetros espaciais quando se estuda o efeito da fragmentação sobre a extinção de espécies (Metzger, 1999a).

Foram encontradas espécies pouco influenciadas pela maioria dos índices e que se relacionam com o índice de distância do vizinho mais próximo (índice de isolamento), sendo elas: Lonchocarpus muehlbergians, Maytenus aquifolium, Strychnos brasiliensis, Rollinia sylvatica, Peschiera australis e Piper xylosteoides. Todas essas espécies foram consideradas raras por Rodrigues (1998a) quando observadas em um estudo realizado nos mesmos fragmentos utilizados no presente trabalho.

As espécies Sebastiania commersoniana, Machaerium aculeatum, Casearia obliqua e duas espécies da família Lauraceae foram as que apresentaram maior correlação com os índices de área, área central e forma. E também que melhor descrevem a composição de espécies na borda do fragmento "Paiquerê", que possui forte correlação com os índices acima citados.

"Paiquerê" e "Pastejo" foram os fragmentos que mais diferiram na composição de espécies em suas bordas dos demais fragmentos e entre si. "Pastejo" não possui correlação com nenhum dos índices estudados no presente trabalho. Três fragmentos formam um grupo que possui uma pequena diferença na composição de espécies quando comparados com a grande maioria, e são eles: "Vagabundo", "Broken Elba" e "Placa". Os outros 13 fragmentos apresentam composição de espécies muito similar. Em estudo realizado por Metzger (2000), a composição de espécies de árvores entre fragmentos também variou; segundo autor, há influência do fragmento e do arranjo da paisagem na diversidade e composição de espécies de árvores, sendo que a estrutura da paisagem (fragmentos circunvizinhos) pode ser tão importante quanto a área do fragmento controlando esta diversidade de espécies.

Os valores dos índices de forma (F) (Tabela 3) mostram que os fragmentos equivalem a círculos, quadrados e retângulos de lados X e 10X, e somente um fragmento ("Godoy" - 2.371,14 ha) possui um índice de forma muito maior $(7,08)$, equivalendo a um retângulo de lados $\mathrm{X}$ e 100X. Embora este fragmento tenha um formato bem alongado, a área total e a porcentagem de área central deste é superior a todos os outros fragmentos estudados, ou seja, seu tamanho compensa sua forma.

Tabela 3. Valores de área, índice de área central e índice de forma para os 19 fragmentos estudados na região de Londrina - PR.

Table 3. Area values, index of central area and form index for the 19 fragments studied in the area of Londrina - PR.

\begin{tabular}{lccc}
\hline Fragmentos & $\begin{array}{c}\text { Área dos fragmentos } \\
\text { (ha) }\end{array}$ & $\begin{array}{c}\text { Índice de área central } \\
(\%)\end{array}$ & $\begin{array}{c}\text { Valor do índice de } \\
\text { forma (F) }\end{array}$ \\
\hline Zélia & 12,33 & 37,04 & 1,11 \\
Mãe morta & 1,71 & 31,58 & 1,15 \\
Eucalyptus & 2,70 & 40,00 & 1,28 \\
Pastejo & 74,07 & 36,36 & 1,67 \\
Godoy & 2371,14 & 87,73 & 7,08 \\
Doralice & 71,91 & 73,34 & 2,81 \\
Perdidão & 24,75 & 78,18 & 1,33 \\
Perdidinho & 8,91 & 64,65 & 1,21 \\
Broken Elba & 1,90 & 4,44 & 0,94 \\
Futebol & 1,80 & 0,00 & 1,02 \\
Vagabundo & 2,07 & 39,13 & 1,15 \\
Paiquerê-twins & 84,42 & 85,59 & 1,57 \\
Placa & 1,44 & 18,75 & 1,13 \\
Tânia & 1,17 & 7,69 & 1,53 \\
Paulo & 4,68 & 26,92 & 2,15 \\
Clube de meninos & 1,91 & 0,00 & 0,99 \\
Extremo norte & 1,35 & 26,67 & 1,29 \\
Saco cheio & 3,33 & 45,95 & 1,32 \\
\hline
\end{tabular}


Ainda quanto ao formato dos fragmentos, dez dos dezoito fragmentos apresentaram formato mais próximo do circular, divergindo do encontrado por Paula (2001), onde a maioria dos fragmentos dos recortes do norte do Paraná possuíam formato retangulare. O mesmo autor cita que os fragmentos maiores tendem a ter formato retangular, concordando com o presente estudo, onde os três maiores fragmentos, tendo estes grande diferença de tamanho para os demais, possuem forma retangular.

A média ponderada total para distância de todas as espécies foi de 16,77 metros da borda. Foram encontradas espécies que tendem a ser susceptíveis à fragmentação florestal, uma vez que estão fortemente relacionadas com os índices de fragmentos e da paisagem (Tabela 4). Estas espécies necessitam de fragmentos maiores e com um bom nível de conservação. Segundo Metzger (1999a), a extinção de espécies está relacionada com a perda de área, que reduz a heterogeneidade interna do habitat, além do aumento da área sob efeito de borda. A maioria das espécies citadas acima ocorre com mais freqüência no fragmento "Paiquerê", podendo este ser indicado como fragmento prioritário em termos de conservação.

Tabela 4. Espécies encontradas nos remanescentes florestais com forte relação com os índices de fragmentos e da paisagem.

Table 4. Species found in the forest remnant with strong relation with the index of fragments and the landscape.

\begin{tabular}{|c|c|}
\hline \multirow[t]{2}{*}{ ACANTHACEAE } & Geissomeria pubescens Nees \\
\hline & Justicia brasiliana Roth. \\
\hline ARECACEAE & Euterpe edulis Mart \\
\hline CARICACEAE & Jacaratia spinosa (Aubl.) A.DC. \\
\hline \multirow[t]{2}{*}{ EUPHORBIACEAE } & Acalypha gracilis A. Gray \\
\hline & Sebastiana commersoniana (Baill) Sm. \& Dawms \\
\hline \multirow[t]{5}{*}{ FLACOURTIACEAE } & Banara parviflora (Ag. Gray) Bentham \\
\hline & Casearia decandra Jacq \\
\hline & Casearia obliqua Spr. \\
\hline & Casearia sylvestris Swartz \\
\hline & Prockia crucis P. Bromne ex L. \\
\hline ICACINACEAE & Citronela megaphylla (Miers) Howard. \\
\hline \multirow[t]{2}{*}{ LAURACEAE } & Lausp 2 \\
\hline & Nectandra megapotamica (Spr.) Mez \\
\hline \multirow[t]{3}{*}{ LEGUMINOSAE } & Bauhinia forficata Link. \\
\hline & Lonchocarpus campestris Mart. Ex Bentham \\
\hline & Machaerium aculeatum Raddi \\
\hline MELASTOMATACEAE & Miconia tristis Spring \\
\hline \multirow{2}{*}{ MELIACEAE } & Cedrela fissilis Vell. \\
\hline & Trichilia clausseni C. DC. \\
\hline MYRSINACEAE & Myrsine lanceolata Mez \\
\hline MYRTACEAE & Campomanesia xanthocarpa Berg. \\
\hline \multirow[t]{2}{*}{ PIPERACEAE } & Piper aduncum Linn. \\
\hline & Piper glabratum Kunth. \\
\hline RHAMNACEAE & Colubrina glandulosa Perk \\
\hline RUTACEAE & Esenbeckia febrifuga (St. Hill.) A. Juss. \\
\hline SOLANACEAE & Cestrum calycinum Willd. \\
\hline VERBENACEAE & Aegiphila sellowiana Cham. \\
\hline
\end{tabular}

\section{CONCLUSÕES}

Os índices ou métricas da paisagem relacionados com a composição de espécies de arvoretas e que, portanto, podem estar agindo na determinação de riqueza dos fragmentos estudados foram: o coeficiente de variação de tamanho do fragmento na paisagem e os índices de área, área central e forma dos fragmentos.

Os índices da paisagem que apresentaram maior importância por explicarem a maioria da variação das espécies de arvoretas nas bordas dos fragmentos florestais foram: área do fragmento, forma do fragmento e área central do fragmento. Estes índices da paisagem devem ser observados quando 
houver a necessidade de fragmentação de áreas ainda intactas em outras regiões, para que haja o menor impacto possível sobre a biodiversidade da região.

\section{REFERÊNCIAS}

BRAAK, C. J. F. CANOCO - a program for canonical community ordination by partial detrended canonical correspondence analysis and redundancy. Version 2.1. Technical Reports: LWA-88-02. Netherlands, 1988.

COLWELL, R. C. BIOTA program: The Biodiversity Database Manager. Cambridge, Massachussets. Version 1.5.0, 1999.

CORREA, A. R.; GODOY, H.; BERNARDES, L. R. M. Circular Técnica IAPAR: 5: Características climáticas de Londrina. Londrina, 1982.16p.

FARINA, A. Principles and methods in landscape ecology. London: Chapman \& Hall Ltd, 1998.

McCUNE, B. \& MEFFORD, M. J. PC-ORD: Multivariate analysis of ecological data (version 4). MjM Software Design, Gleneden Beach, Oregon, 1999.

METZGER, J. P. Estrutura da paisagem e fragmentação: análise bibliográfica. Anais da Academia Brasileira de Ciência, v. 71, n. 3 (1), p. 445 - 463. 1999a.

METZGER, J. P. Delineamento de experimentos numa perspectiva de ecologia da paisagem. Instituto de Biociências - USP (no prelo). 1999b.

METZGER, J. P. Quantificação da estrutura da paisagem: o uso adequado de métricas. Instituto de Biociências - USP (no prelo). 1999c.

METZGER, J. P. Tree functional group richness and landscape structure in Brazilian tropical fragmented landscape. Ecological Applications, v. 10, n. 4, p. 1147 - 1161. 2000.

PAULA, A. S. Degradação da paisagem norte-paranaense: um estudo de fragmentos florestais. Londrina. 2001. 27 f. Dissertação (Mestrado em Agronomia) - Universidade Estadual de Londrina.

RODRIGUES, E. Edge effects on the regeneration of fragments in south Brazil. Cambridge, 1998 a. 172 f. D. Phil. Dissertation - Harvard University,.

RODRIGUES, E. Efeito de bordas em fragmentos de floresta. Cadernos da Biodiversidade, Curitiba, v. 1, n. 2, p. 1-5. 1998b.

RODRIGUES, E. Ecologia de fragmentos florestais no gradiente urbano de Londrina. São Carlos. 1993. 110f. Dissertação (Mestrado) - Universidade de São Paulo.

SCHIEROLZ, T. Dinâmica biológica de fragmentos florestais. Ciência Hoje, v. 12, p. 22-29. 1991.

VELOSO, H. P.; GÓES F ${ }^{\circ}$, L. Fitogeografia brasileira: classificação fisionômico-ecológica da vegetação neotropical. Projeto Radambrasil, Série Vegetação, n. 1. Salvador. 1982. 85 p.

VOLOTÃO, C. F. S. Trabalho de análise espacial - métricas do Fragstats. 1998. 45 f. Trabalho de análise espacial do curso de mestrado do INPE - São José dos Campos. 